\title{
PRIMARY ACTINOMYCOSIS OF BREAST - A RARE DISEASE
}

M. Madan ${ }^{1}$, K. Nischal ${ }^{2}$, Avinash $\mathrm{P}^{3}$

\section{HOW TO CITE THIS ARTICLE:}

M. Madan, K. Nischal, Avinash P. "Primary actinomycosis of breast - a rare disease". Journal of Evolution of Medical and Dental Sciences 2013; Vol2, Issue 29, July 22; Page: 5495-5498.

ABSTRACT: Primary actinomycosis of the breast is a rare disease, with fewer than twenty cases reported since its description by Ammentorp in 1893. Breast actinomycosis is primary when inoculation occurs through the nipple. In this patient in our study, mammography suggested a diagnosis of inflammatory carcinoma that pathological examinations later confirmed as actinomycosis. In addition this study represents the first report of primary breast actinomycosis in post menopausal woman in India and $4^{\text {th }}$ in world.

KEY WORDS: Actinomycosis, Breast, Post menopausal, Mammography

INTRODUCTION: Primary actinomycosis of the breast is a rare disease, with fewer than twenty cases reported since its description by Ammentorp in 1893[1, 2]. Breast actinomycosis is primary when inoculation occurs through the nipple. Secondary actinomycosis of the breast refers to the extension of pulmonary infection through the thoracic cage in a process that can affect the ribs, muscles and finally the breast. Distinguishing actinomycosis from more common breast lesions such as inflammatory carcinoma is difficult. Gogas et al [3] reported that diagnosis is frequently made after surgery. In this patient in our study, mammography suggested a diagnosis of inflammatory carcinoma that pathological examinations later confirmed as actinomycosis. In addition this study represents the first report of primary breast actinomycosis in post menopausal woman in India and 4th in world.

CASE REPORT: A 55 year old post menopausal female patient was admitted on 5-2-2008 with complaints of swelling in the right breast since three months, insidious in onset and was a size of lemon $(2 \times 3 \mathrm{~cm})$ in the middle and outer quadrant of the right breast gradually progressed to the present size $(4 \times 5 \mathrm{~cm})$. Patient had fever and was treated by local doctor. Complains of dull aching pain at the lump site.

\section{LOCAL EXAMINATION:}

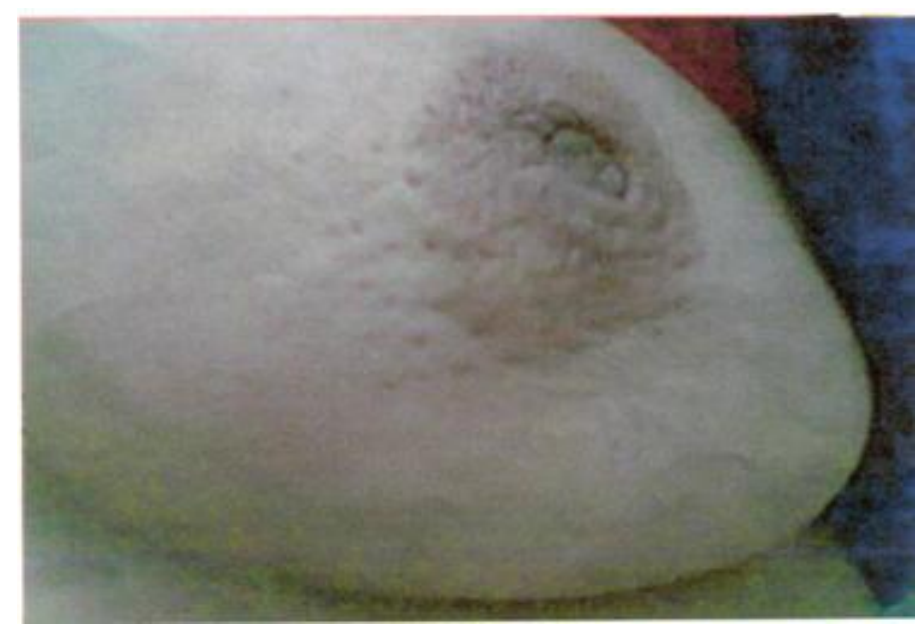

Figure 1: Clinical Picture 


\section{INSPECTION:}

Left side breast appears normal,

Right side fullness present in the middle and outer quadrant,

The nipple inverted and areola appears distorted mild on right side.

\section{PALPATION:}

Globular lump measuring about $4 * 5 \mathrm{~cm}$ palpable in the retroareolar and upper outer quadrant of the right breast.

The skin is pinchable (free from the lump).The lump is fixed to the breast tissue and moves with the tissue, No edema, discharge, chest wall fixity. There is 2 palpable lymph node in the right axilla,

PROVISIONAL DIAGNOSIS: Carcinoma breast

Stage 2 (T2 N1 MO).

INVESTIGATIONS: HB - 7.99 GMS\%

FNAC - C 175/08:- Inflammatory changes seen with clusters of atypical ductal hyperplastic cells. Features suggestive of inflammatory carcinoma breast.

Other investigations were within normal limit.

SURGERY- MODIFIED RADICAL MASTECTOMY.

HISTOPATHOLOGY- Features suggestive of actinomycosis with multiple micro abscess.

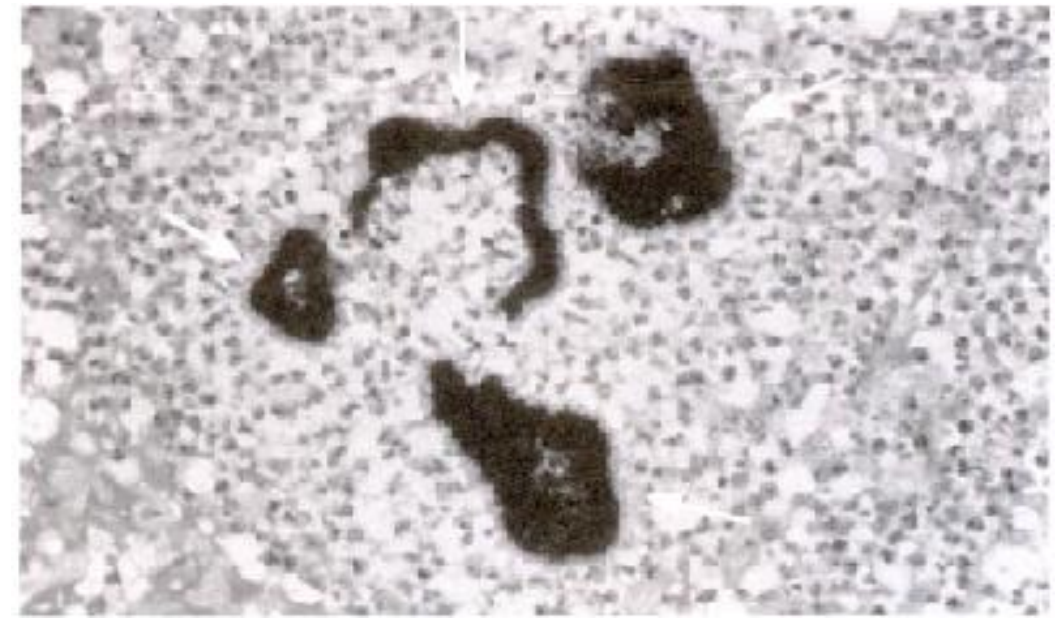

Figure 2:

Filamentous branching bacteria (arrows) positive to silver impregnation, characteristic of grains of Actinomyces israelii. 


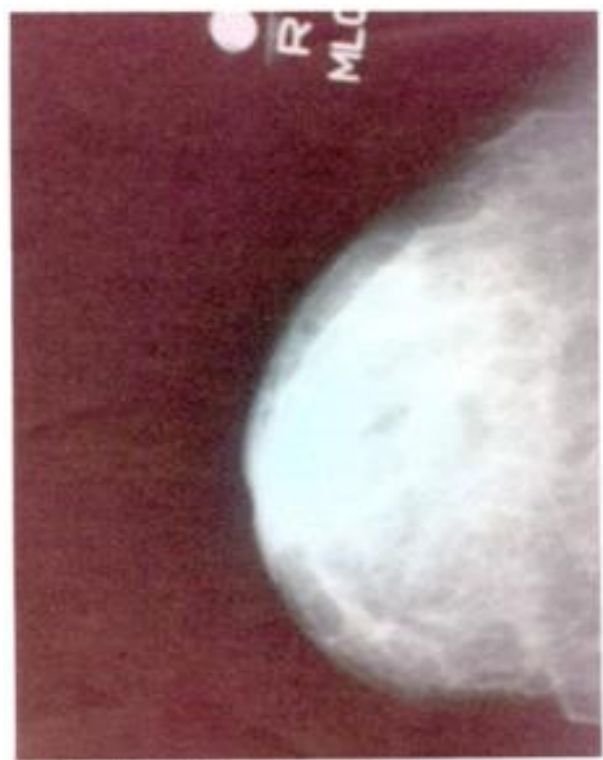

Figure :3 Mammography

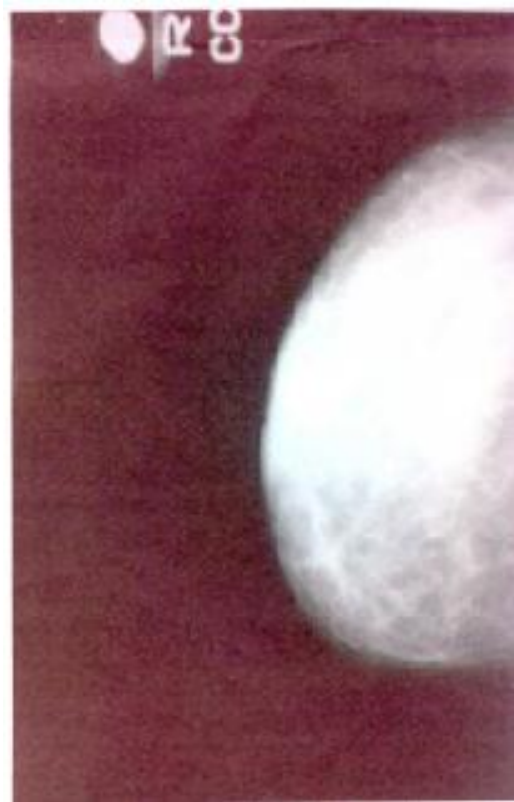

Figure :4 Mammography

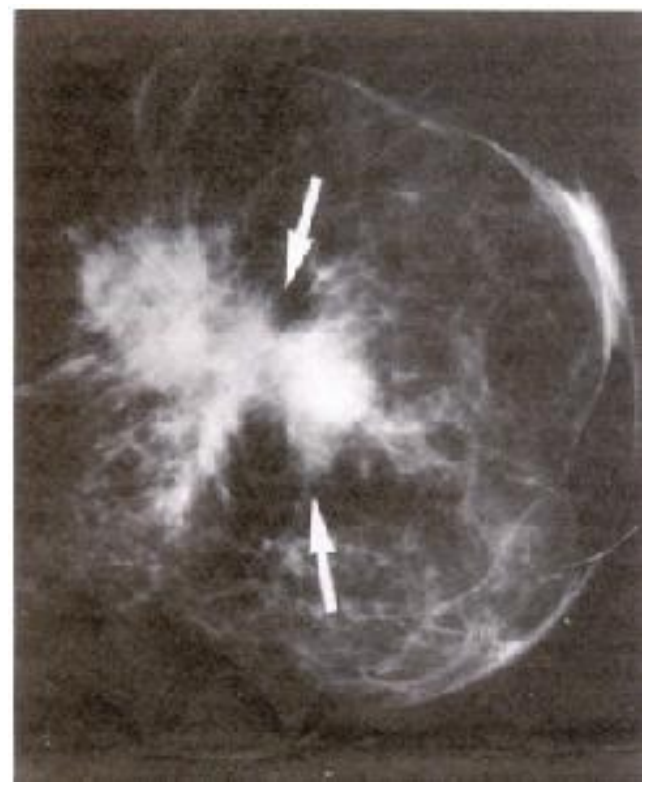

Figure: 5

Craniocaudal right mammogram, overexposed, shows speculated mass (arrows).

DISCUSSION: Actinomycosis is caused by gram-positive anaerobic filamentous bacteria that are part of the normal oral flora $[1,4]$. The most frequent cause is A. israelii, present in $78 \%$ of patients [5]. Usually, actinomycosis represents a chronic infection characterized by pus, fibrosis, and fistulas that drain sulfur granules.

Primary actinomycosis of the breast starts at the nipple; most of the abscesses are retro papillary [1]. Possible causes of this condition observed by Cope and quoted by Lloyd-Davies [1] include trauma, lactation, and kissing. All reported cases of actinomycosis of the breast have involved premenopausal women. This study represents the first case report of primary actinomycosis of the breast in a postmenopausal woman. 
Actinomycosis of the breast usually presents as a recurrent abscess, often retro papillary. Fistulas and purulent or bloody discharge from sinuses may occur. In the most advanced cases of long duration, fibrosis with local cicatrization and architectural distortion of the breast tissue are present [1].

The diagnosis is made by pathologic examination of the biopsy or mastectomy specimen, in which we can see the characteristic sulfur granules representing the bacterial colonies. Pathologic examination in cases of actinomycosis usually reveals non-acid-fast gram-positive organisms with filamentous branching that appear grossly as sulfur granules.

ACKNOWLEDGEMENTS: we sincerely thank the co-operation and help from Dr. Umesh. K-prof of radiology, Dr.Aparna.N-assoc professor dept of pathology, and Dr. Naveen. H.M \& Dr. Harish. B.K - post graduates in surgery and but not the least all my staff.

\section{REFERENCES:}

1. 1.Lloyd-Davies JA. Primary actinomycosis of the breast. Br J Surg 1951; 38:378 -381

2. Pinto MM, Longstreth GB, Khoury GM. Fine needle aspiration of Actinomyces infection of the breast: a novel presentation of thoraco pleural actinomycosis. Acta Cytol 1991; 35:409-411

3. Gogas J, Sechas M, Diamantis S, Sbotos C. Actinomycosis of the breast. Int Surg 1972; 57: $664-665$.

4. Weese WC, Smith 1M. A study of 57 cases of actinomycosis over a 36-year period: a diagnostic "failure" with good prognosis after treatment. Arch Intern Med 1975; 135:1562-1568

5. Lerner PI. Actinomycoses. In: Harrison TR, ed. Medicina interna. Rio de Janeiro: McGraw-Hill, 1995:732 -735

\section{AUTHORS:}

1. M. Madan

2. K. Nischal

3. Avinash. P

\section{PARTICULARS OF CONTRIBUTORS:}

1. Professor \& HOD, Department of Surgery, Sri Devaraja Urs Medical College, Tamaka, Kolar.

2. Associate Professor, Department of Surgery, Sri Devaraja Urs Medical College, Tamaka, Kolar.
3. Post Graduate, Department of Surgery, Sri Devaraja Urs Medical College, Tamaka, Kolar.

\section{NAME ADRRESS EMAIL ID OF THE CORRESPONDING AUTHOR:}

Dr. K. Nischal,

Sri devaraj Urs Medical College,

Tamaka, Kolar.

Email- knischal697@gmail.com

Date of Submission: 28/06/2013.

Date of Peer Review: 02/07/2013.

Date of Acceptance: 19/07/2013.

Date of Publishing: 22/07/2013 